\title{
Práticas de Ensino e Uso das Tecnologias no Atendimento Educacional Especializado: enfoque nas salas de recursos multifuncionais
}

\author{
Mozanilde Santos Nunes Cabral - mozaneka@ hotmail.com - PGCult - UFMA \\ João Batista Bottentuit Junior - jbbj@ terra.com.br - PGCult - PPGEEB - UFMA
}

Resumo: O presente estudo tem como objetivo conhecer e analisar trabalhos acadêmicos que abordam a questão do uso das TIC como recurso pedagógico no Atendimento Educacional Especializado (AEE), realizado nas Salas de Recursos. Os dados foram coletados em bases de dados eletrônicas e repositórios digitais de acesso aberto. A análise dos resultados foi efetivada a partir do arranjo e identificação de algumas categorias relacionadas aos recursos utilizados, público atendido, percepções docentes sobre os potenciais e benefícios aos alunos, reações dos discentes frente ao uso desses recursos e os desafios que envolvem a adoção dessas práticas. Os resultados demonstram que apesar dos docentes em AEE terem uma visão positiva em relação aos potenciais desses recursos, as práticas ainda são limitadas devido a várias dificuldades enfrentadas pelos mesmos, como a falta de Internet, de apoio técnico, a carência de equipamentos e de manutenção dos mesmos ou ainda, falta de conhecimentos sobre as tecnologias.

Palavras-chave: Salas de Recursos Multifuncionais. Atendimento Educacional Especializado. Tecnologias de Informação e Comunicação. Tecnologias Digitais.

\section{Teaching Practices and Use of Technologies in Educational Specialized Service:}

\section{focus on multifunctional features rooms}

\begin{abstract}
This study aims to evaluate and analyze academic papers that address the issue of the use of ICT as a teaching resource in the Educational Service Specialist (ESA), held in the Resource Rooms. Data was collected in electronic databases and digital repositories of open access. The data analysis was carried from the arrangement and identification of some categories related to the resources used, attended public, teachers perceptions about the potential and benefits to students, reactions of students against the use of these resources and the challenges surrounding the adoption of these practices. The results show that although teachers in ESA have a positive view about the potential of these resources, the practices are still limited due to various difficulties faced by them, such as lack of Internet, technical support, lack of equipment and maintenance thereof or lack of knowledge about technologies.
\end{abstract}

Keywords: Resource Rooms. Specialized Educational Service. Information and Communication Technologies. Digital Technologies.

\section{INTRODUÇÃO}

No âmbito da escola, no início do século XXI, presenciamos o fortalecimento do movimento de inclusão escolar, o que tem favorecido o deslocamento dos serviços da educação especial para as escolas regulares. Paralelamente, a sociedade vivencia nesse período uma revolução das Tecnologias da Informação e Comunicação (TIC), as quais se propagam e impactam todas as esferas sociais.

O deslocamento da educação especial para as escolas regulares tornou-se uma oportunidade de mudança para os profissionais dessa área, uma vez que neste cenário, as ações a serem desenvolvidas pelos especialistas adquiriram status de complementaridade no processo de escolarização e aprendizagem dos alunos.

Diante dessa realidade, compreende-se que entre os inúmeros desafios que os profissionais da educação especial terão que enfrentar, coloca-se a exigência de repensar suas práticas pedagógicas e incorporar os recursos das Tecnologias da Informação e Comunicação - principalmente as Tecnologias Digitais nos serviços 
ofertados ao público da educação especial, como forma de comportar novas e significativas experiências de aprendizagem para esses alunos.

No caso específico das tecnologias digitais, vivemos um momento impar na história das revoluções tecnológicas, já que em virtude de suas próprias características ocorre um progressivo e veloz desenvolvimento desses instrumentos e por consequência influenciam e transformam as relações sociais continuamente. "Mais recentemente, o avanço da tecnologia digital (notebooks, celulares, ipads e redes sem fio, entre outros) conferiu maior portabilidade às TIC, tornando as práticas de comunicação em meio digital cada vez mais presentes em contextos sociais formais e informais" (BRAGA, 2013, p. 77). O presente estudo teve como objetivo geral realizar um levantamento de trabalhos acadêmicos que focam a temática da utilização das tecnologias digitais como recursos pedagógicos, no Atendimento Educacional Especializado ofertado nas Salas de Recursos Multifuncionais, realizadas por pesquisadores brasileiros no período de 2000 a 2015. Os objetivos específicos foram:

- Verificar quais são os recursos das TIC que estão sendo adotados no AEE das Salas de Recursos e o público-alvo dessas práticas;

- Conhecer e analisar os principais aspectos relacionados ao uso das TIC no AEE que estão sendo abordados nas investigações acadêmicas.

Assim, o presente estudo justifica-se pela contribuição para a discussão acerca da utilização dessas novas tecnologias como instrumento de ensino no AEE realizado nos espaços das Salas de Recursos e apresenta um recorte da situação acerca das práticas já desenvolvidas pelos especialistas em AEE nesses ambientes de aprendizagem.

\section{AEE: O QUE É, ONDE DEVE OCORRER E QUEM REALIZA?}

O Atendimento Educacional Especializado (AEE) é um serviço da educação especial que se caracteriza como uma proposta de apoio aos alunos dessa modalidade educacional, no sentido de ofertar práticas pedagógicas estratégicas e recursos que favoreçam o desenvolvimento integral dos mesmos e a efetivação do seu processo de escolarização. O AEE é um serviço da Educação Especial que [...] deve ser articulado com a proposta da escola regular, embora suas atividades se diferenciem das realizadas em salas de aula de ensino comum (BRASIL, 2009).

O AEE é um direito assegurado pela Constituição brasileira de 88 às pessoas com deficiência. Nesse texto consta no artigo 208, inciso 3 que "o dever do Estado com a educação será efetivado mediante a garantia de [...] atendimento educacional especializado aos portadores de deficiência, preferencialmente na rede regular de ensino" (BRASIL, 2008).

As Diretrizes Operacionais para o Atendimento Educacional Especializado na Educação Básica, modalidade Educação Especial (Res. no 4, de 2 de Out. de 2009) assinalam no artigo $2^{\circ}$ : o AEE tem como função complementar ou suplementar a formação do aluno por meio da disponibilização de serviços, recursos de acessibilidade e estratégias que eliminem as barreiras para sua plena participação na sociedade e desenvolvimento de sua aprendizagem. (BRASIL, 2009). No que diz respeito à caracterização do AEE e sua função em relação ao processo de escolarização do público alvo da educação especial, o documento que orienta a Política Nacional na Perspectiva da Educação Inclusiva explicita que:

[...]. As atividades desenvolvidas no atendimento educacional especializado diferenciam-se daquelas realizadas na sala de aula comum, não sendo substitutivas à escolarização. Esse atendimento complementa e/ou suplementa a formação dos alunos com vistas à autonomia e independência na escola e fora dela (BRASIL, 2008). 
Sobre as formas de atendimento educacional especializado a serem ofertadas, as diretrizes para a educação especial, apontam no artigo $8^{\circ}$ que as escolas devem prover serviços de apoio pedagógico especializado: nas classes comuns, mediante atuação de professor da educação especial, professores intérpretes das linguagens e códigos aplicáveis e de outros profissionais; itinerância intra e interinstitucional e outros apoios necessários à aprendizagem, à locomoção e à comunicação; em salas de recursos, nas quais o professor da educação especial realiza a complementação e/ou suplementação curricular, utilizando equipamentos e materiais específicos (MINETTO, 2008, p. 24).

Quanto ao local de oferta do AEE, segundo as orientações das Diretrizes operacionais para a educação especial o artigo $5^{\circ}$ prescreve que este deve ser realizado prioritariamente, nas salas de recursos da própria escola ou de outra escola regular. Essas Diretrizes também prenunciam que o AEE pode ocorrer em centros de atendimentos (BRASIL, MEC/CNE/CEB, 2009). As Salas de Recursos Multifuncionais (SEM) são espaços criados pelo Programa de Implantação das Salas de Recursos Multifuncionais, do Governo Federal (Portaria normativa do MEC, $n^{\circ} 13$, de 24 de abril de 2007) que objetiva apoiar a organização e oferta do AEE na rede regular de ensino para o público da educação especial. Sobre essas Salas, Denise Alves et al. (2006) esclarecem que são espaços onde se desenvolvem um atendimento diferenciado, favorável para o desenvolvimento das capacidades do alunado da educação especial, que favorece a efetivação do processo de escolarização dos mesmos.

\begin{abstract}
As salas de recursos multifuncionais são espaços da escola onde se realiza o atendimento educacional especializado para alunos com necessidades educacionais especiais, por meio do desenvolvimento de estratégias de aprendizagem, centradas em um novo fazer pedagógico que favoreça a construção de conhecimentos pelos alunos (ALVES, et. al., 2006, p. 13).
\end{abstract}

Em relação à estrutura física e os equipamentos presentes nesses lugares, o Decreto $n^{\circ} 7.611$, de 17 de novembro de 2011 , em seu artigo $5^{\circ}$, $\S 3^{\circ}$ traz uma definição específica: "as salas de recursos multifuncionais são ambientes dotados de equipamentos, mobiliários e materiais didáticos e pedagógicos para a oferta do atendimento educacional especializado". Nesse contexto, de desafios à educação especial, é válido conhecer e refletir sobre as práticas vivenciadas por esses especialistas e trazer à tona questões pertinentes às investigações acadêmicas e institucionais que provoquem as trocas de saberes nessa área.

\title{
PROCEDIMENTO METODOLÓGICO
}

A pesquisa é de natureza qualitativa, pois é elaborada com base em dados subjetivos e outros níveis de consciência e não tem a ambição de mensurar variáveis, mas considerar qualitativamente os resultados levantados na investigação (SANTOS; CANDELORO, 2006, p. 71). Na visão das citadas autoras quanto ao delineamento, à mesma apresenta contornos de estudo descritivo-exploratório, já que intenta proporcionar uma ampla visão sobre o tema tratado, a partir de levantamento bibliográfico e/ou documental (p. 73).

Para a coleta de dados, realizou-se a busca de trabalhos acadêmicos disponíveis em algumas bases de dados eletrônicas e repositórios digitais de acesso aberto como: Lume - Repositório digital da UFRGS, Biblioteca Digital Brasileira de Teses e Dissertações, SIBi da USP, Repositório Institucional da UnB, Portal de Periódicos CAPES/MEC, Banco de Teses /CAPES, Scielo e Google Acadêmico.

Como estratégia para delimitar o universo da pesquisa, utilizou-se no processo de busca os mecanismos de busca avançada, a partir da combinação das seguintes 
palavras -chave: Atendimento Educacional Especializado, Salas de Recursos, Educação Especial, Tecnologias Digitais, Mídias Digitais e Tecnologias da Informação e Comunicação. A pesar de identificarmos na legislação que o termo sala de recursos multifuncionais é o termo correto e também definido e adotado em documentos legais, muitas escolas e também estudos publicados o termo "multifuncionais" é omitido, ficando apenas sala de recursos. Durante o recenseamento de trabalhos para este estudo foram poucos os trabalhos onde o termo "multifuncional" apareceu nos estudos.

Durante a seleção dos documentos - alvo, a eleição dos mesmos obedeceu aos seguintes critérios: primeiramente, a partir dos títulos e palavras-chaves; na sequência realizou-se a leitura dos resumos dos textos pré-selecionados; no caso dos textos em que os resumos não foram esclarecedores quanto ao conteúdo específico da pesquisa realizada, fez-se uma leitura complementar dos sumários e por último realizou-se a leitura integral dos textos de interesse para o estudo pretendido.

A busca seguiu ainda alguns critérios adicionais: sobre o marco temporal, limitou-se ao intervalo de tempo que se situa entre 2000 a 2015. Esse período foi escolhido porque abrange um momento em que ocorreu um avanço tecnológico significativo - particularmente em relação ao período de expansão das Salas de Recursos Multifuncionais nas diversas regiões do país. Quanto à abrangência, restringiu-se somente a pesquisas nacionais, contemplando o objetivo de fazer um recorte sobre a realidade nacional acerca da temática aqui abordada.

É válido ressaltar, que o propósito deste estudo foi de obter um recorte da realidade, ainda que as buscas tenham sido circunscritas as bases de dados eletrônicas citadas e havendo, pois, a possibilidade de que o mesmo não contemple toda a realidade Brasileira acerca da produção acadêmica pertinente ao tema estudado, satisfez aos objetivos pretendidos. Quanto ao período em que foi realizada esta investigação, compreendeu os meses de Novembro e Dezembro de 2015. Para subsidiar a construção deste artigo recorreu-se a alguns documentos normativos que tratam sobre o AEE, Salas de Recursos Multifuncionais, Especialistas em AEE, além de apresentar as contribuições de alguns autores que discutem a utilização das Tecnologias da Informação e Comunicação na educação especial.

\section{APRESENTAÇÃO E ANÁLISES DOS RESULTADOS}

Como resultado da busca realizada nas bases de dados já mencionadas, foram encontrados inicialmente 217 trabalhos. Contudo, após o procedimento de triagem dos mesmos, selecionou-se 10 que atendem aos objetivos deste estudo.

$\mathrm{Na}$ análise dos resultados adotou-se o arranjo em categorias identificadas e relacionadas à proposta geral da pesquisa e os objetivos pretendidos. Conforme BorgesAndrade et. al. (2007, p.527) é interessante no processo de análise à criação e/ou identificação de categorias, - o que pode ser feito antes ou depois da análise dos dados entendendo que esse procedimento "define de forma fundamental o nível de exploração da análise qualitativa de dados, tendo em vista que a definição a priori já indica um grau de conhecimento inicial sobre a matéria em estudo".

Partindo desse entendimento, a análise permitiu a organização dos resultados em 6 categorias a saber: (1) especificação dos trabalhos usados no estudo quanto ao foco de abordagem; (2) tecnologias/recursos utilizados como Instrumentos pedagógicos nas Salas de Recursos; (3) público atendido nas Salas de Recursos que utilizaram as TIC no AEE; (4) visões dos docentes do AEE sobre o potencial das novas tecnologias utilizadas no Atendimento e os benefícios da utilização das novas tecnologias para os alunos; (5) percepções em relação às reações dos alunos quando utilizam as tecnologias; e (6) dificuldades identificadas no processo de utilização das tecnologias nas Salas de 
Recursos. Quanto a especificação e categorias dos trabalhos selecionados, identificou-se 3 artigos, 4 Monografias de Especialização e 2 Dissertações de Mestrado. Na busca realizada não foi possível recensear nenhuma Teses de Doutorado. No entanto, sobre o quantitativo comparativo desses trabalhos acadêmicos considera-se que o recorte da pesquisa não possibilita uma análise precisa.

Verifica-se que na maioria dos trabalhos consta a terminologia AEE e não Educação Especial nos títulos, palavras-chaves e resumos, sugerindo uma distinção entre ambas, já que os documentos normativos que orientam essa modalidade educacional e que tratam das SRM qualificam os serviços, recursos e atividades pedagógicas realizadas nesses ambientes como AEE e prescrevem a educação especial como a modalidade de educação que deve permear todas as etapas, níveis e modalidades educacionais de forma transversal. O AEE é compreendido, portanto, como parte constitutiva das ações da educação especial. Também a terminologia Necessidades Educacionais Especiais (NEE), já aparece como uma alternativa para se referir aos alunos que apresentam necessidades educacionais específicas, possibilitando que o AEE seja compreendido como um atendimento que pode ser ofertado a alunos que apresentam dificuldades no processo de escolarização e que ainda não se encontram nas definições prescritas pelos dispositivos legais que tratam do público-alvo da educação especial. Dessa forma, amplia-se o público que pode receber um atendimento específico que visa contribuir com a melhoria do desempenho escolar.

\begin{tabular}{cl} 
Quadro 1: Especificação dos trabalhos utilizados no estudo quanto ao foco de abordagem \\
\hline Trabalho & Foco do trabalho \\
A & Objetos de Aprendizagem Digitais nas Salas de Recursos \\
B & Utilização dos Recursos de Informática nas Salas de Recursos \\
C & Tecnologias da Informação e Comunicação nas Salas de Recursos \\
D & Mídias no AEE \\
E & Informática e Inclusão de Alunos com Necessidades Especiais \\
F & Mídias na Aprendizagem de alunos com Necessidades Educacionais Especiais \\
G & O Computador e a Internet nas Salas de Recursos \\
H & Sistematização do AEE e uso do Computador \\
I & Tecnologias da Informação e Comunicação nas Salas de Recursos \\
J & AEE e o uso das Tecnologias nas Salas de Recursos do Ensino Médio \\
\hline
\end{tabular}

Sobre as tecnologias incorporadas às práticas pedagógicas nas Salas de Recursos, de maneira geral há uma quantidade significativa de recursos utilizados, embora muitos se restrinjam ao uso do computador direcionado mais aos softwares aplicativos e de Jogos. Constata-se também o uso de diversos tipos de objetos de aprendizagem e são apontados alguns recursos específicos da Internet, como o Google, Facebook, jogos online, sites de notícias entre outros. Porém, percebe-se que diante da diversidade de recursos hoje disponíveis na Internet, o uso dos mesmos no AEE ainda é bastante limitado.

Nessa análise, merece destaque as condições de acesso à internet nas escolas, que se apresentam muito desiguais nas diversas localidades do país e principalmente para os grupos sociais mais marginalizados. Diante dessa situação, concorda-se com Sorj e Guedes (2005, p. 116) quando afirmam que "uma política de universalização do acesso à Internet deve ter como objetivo prioritário a rede escolar, único local onde pode ser efetivamente atingido o conjunto da população". Inversamente, o que se observa em muitas realidades escolares é a ausência de Internet nesses ambientes, o que mostra que ainda não temos políticas públicas efetivas para resolver essa problemática. Situação essa, que resulta em obstáculos a exploração das possibilidades dessa tecnologia pelos docentes e discentes e toda comunidade escolar.

Há de se considerar, portanto, o fato de que há dificuldades presentes no cotidiano das escolas que interferem no progresso educacional e na adoção das tecnologias no ensino, como assegura Pedro Demo (2009, p. 113) sobre os entraves à inclusão digital: "não temos máquinas, não temos professores, não temos infraestrutura eletrônica, não temos ambientes escolares". Não obstante, mesmo enfrentando obstáculos, os especialistas têm empreendido 
esforços no sentido de usar recursos digitais em seus atendimentos, como mostra o quadro abaixo no qual estão listadas tecnologias que estão sendo utilizadas pelos docentes nas Salas de Recursos.

Quadro 2: Tecnologias/Recursos Utilizados como Instrumentos Pedagógicos nas Salas de Recursos

\begin{tabular}{|l|l|}
\hline Pesquisa & Tecnologias/Recursos \\
\hline A & Computador, Objeto de Aprendizagem - 'Um dia na Fazenda' \\
\hline B & Computador \\
\hline C & $\begin{array}{l}\text { Computador, vídeos, Internet, Sites de Notícias, Jogos on-line, (memória, tabuada, palavras, raciocínio), } \\
\text { Word, Power Point. }\end{array}$ \\
\hline D & $\begin{array}{l}\text { RIVED, Banco Internacional de Objetos Educacionais, boardmaker Hot Potatoes, Audacity, Mozzila } \\
\text { Composer, Paint, JClic, Jogos Educativos - Gcompris, Tux Paint, Coelho Sabido, Menino Curioso, editores } \\
\text { de histórias em quadrinhos, Jogos em Flash, Escola de Projetos e HagáQuê. }\end{array}$ \\
\hline E & \begin{tabular}{l} 
Computador, Software Cobpaint. \\
\hline F
\end{tabular} \\
\hline G & $\begin{array}{l}\text { Wordpad, Bloco de Notas, Paint, Software Educacional Picolé Digital (aplicativo com 16 jogos Educativos), } \\
\text { Computador e Internet - Softwares: Br-Office, TuxMath, Geogebra, Gimp e TuxPaint. }\end{array}$ \\
\hline H & $\begin{array}{l}\text { Computador: Word, Voki, Paint, google. Tablet - aplicativos educacionais utilizados: ABC Palavras, ABC } \\
\text { do Bita, Soletrando, Play Lab, Puzzle Oceano. }\end{array}$ \\
\hline I & $\begin{array}{l}\text { Computador, Softwares educativos em libras, Dicionário online acessobrasil em libras, } \\
\text { Jogos, SITES e Programas como SEBRAN, ILARIÊ e Facebook. }\end{array}$ \\
\hline J & Computador, Recursos da Internet. \\
\hline
\end{tabular}

Referente ao público atendido com práticas que incorporam as tecnologias percebe-se que praticamente todos os alunos considerados como público-alvo da educação especial, estão tendo experiências significativas com esses artefatos.

Esse resultado evidencia que mesmo sendo necessário avaliar a necessidade específica do aluno no momento da escolha do recurso, pelas múltiplas possibilidades de uso destes, a variabilidade de recursos tecnológicos atualmente disponíveis e a valorização dos potenciais dos alunos, é possível que os profissionais do AEE desenvolvam ricas experiências com o seu alunado. Santos e Pequeno (2011, p. 81) que afirmam "frente às mudanças contemporâneas, existe um ambiente favorável às pessoas com deficiência para atuarem junto às novas tecnologias independentemente de possuírem limitações visuais, físicas, auditivas, mentais ou múltiplas”.

Quadro 3: Público -alvo dos atendimentos

\begin{tabular}{|lcl|}
\hline Deficiência múltipla & Deficiência Mental (Intelectual) & Síndromes em Geral \\
Altas habilidades & Lesão cerebelar /Deficiência Motora & TGD Surdez \\
Deficiência Visual & Deficiência Física & Paralisia Cerebral \\
Transtorno Funcional Específico: TDAH, Dislexia & Deficiência Física \\
\hline
\end{tabular}

Contudo, ressalta-se que essas experiências exigem um planejamento adequado e coerente com cada situação, assim como o empenho dos especialistas em identificar os recursos mais adequados para cada aluno e a disponibilização de recursos de acessibilidade que possam favorecer o uso dos recursos tecnológicos. Demanda da mesma forma, que os profissionais detenham habilidades específicas, fluência na utilização desses instrumentos nas suas práticas de ensino.

De igual modo considera-se que o conhecimento que o professor tem acerca do aluno e suas possibilidades é essencial para permitir essas vivências. Mas é necessário concordar que esse empreendimento de mudança das práticas pedagógicas com o auxílio das tecnologias não é uma tarefa tão fácil nem tão simples, como defende Souza:

Sabe-se que esta mediação da TIC é uma nova atitude frente às questões do conhecimento, de abertura à compreensão de aspectos ocultos do ato de aprender e que o trabalho possui inúmeros desafios para sua implementação, 
pois, exige uma profunda imersão no trabalho cotidiano e na prática. (SOUZA, 2011, p. 45).

Em relação às percepções dos docentes a respeito das potencialidades das tecnologias para o AEE, nota-se que são unânimes em considerar que estes recursos se caracterizam como ambientes propícios à criação e desenvolvimento de práticas educacionais mais interessantes, prazerosas e motivadoras e que permitem novas aprendizagens e favorece o desenvolvimento de novas habilidades e competências para os usuários. Percebe-se, pois, que segundo a visão desses profissionais, a utilização dos recursos digitais apresenta muitos benefícios para os alunos.

Quadro 4: Opinião dos Docentes do AEE sobre o potencial das Tecnologias utilizadas no AEE e os benefícios para os alunos

\begin{tabular}{|c|c|}
\hline $\begin{array}{l}\text { Viabilizam espaços de construção, criação e } \quad \text { reflexão, colaboraçáo, } \\
\text { cooperação e aprendizagem; }\end{array}$ & $\begin{array}{l}\text { Proporciona interação do aluno com o instrumento; } \\
\text { Contribui para o desenvolvimento da autonomia; }\end{array}$ \\
\hline Mais recursos para atender os alunos com Necessidades Especiais; & Eleva a autoestima do sujeito; \\
\hline Ambiente mais atraente e prazeroso; & Exerce influência positiva em relação à atenção e concentração; \\
\hline Instrumento para o desenvolvimento e aprendizagem; & Propicia o desenvolvimento qualitativo dos aspectos afetivo e \\
\hline Instrumento de motivação e estimulação; & cognitivo; Fator de inclusão digital; \\
\hline Valorização do potencial de cada sujeito; & Contato um 'mundo diferente'; \\
\hline Estimula a construção de novos saberes; & Desenvolve o Planejamento (função executora), atenção e memória. \\
\hline Proporcionar ricas experiências não restritas aos ensinos do currículo & Desenvolve a comunicação, coordenação motora; \\
\hline tradicional; & Desenvolvimento das possibilidades dos alunos com NEE; \\
\hline Importante para contextualizar; & Impulsiona a tomada de decisão e escolha de estratégias, respeito às \\
\hline Possibilita vivências e experiências, tornando-as significativas para os & regras impostas; \\
\hline alunos com NEE; & Desenvolve o imaginário; \\
\hline Possibilitam e facilitam o ensino e aprendizagem; & Possibilita o contato com o mundo, através de uma comunicação \\
\hline $\begin{array}{l}\text { Atividades dinâmicas, prazerosas, mais motivadoras e } \\
\text { significativas; Promovem o lúdico e o educativo; }\end{array}$ & diferenciada. \\
\hline Possibilita a vivência/experiência de outras formas de cor & \\
\hline
\end{tabular}

É perceptível a euforia dos docentes em relação às potencialidades das tecnologias para a educação. Quanto a isso, é válido pensar sobre o que diz Demo:

Como depois da euforia costuma vir a desilusão, parece-nos que ambas são impróprias: a euforia é imprópria porque novas tecnologias não reinventam a roda, nem acabam com o passado; a desilusão é imprópria porque é bem possível imaginar horizontes adequados de aprendizagem virtual, sem panaceia e determinismo tecnológico (DEMO, 2009, p. 13).

Desta maneira, é possível que vislumbrando as características positivas das tecnologias, haja mudanças nas práticas pedagógicas, ainda que não cheguem ao ideal almejado, mesmo assim podem ocasionar ganhos para a educação e suas modalidades educacionais e principalmente para os sujeitos envolvidos nessa dinâmica.

Também a observação dos docentes quanto ao comportamento dos alunos frente às tecnologias é bastante positiva. Eles demonstram que os alunos apresentam, entusiasmo, interação, motivação, interesse, fascínio. Estes são apenas alguns dos adjetivos encontrados nas publicações. Este resultado assinala, sem dúvida, uma informação útil para impulsionar a modificação das práticas pedagógicas, tendo em vista que uma das grandes dificuldades enfrentadas pelos professores no seu cotidiano é a falta de interesse e motivação dos alunos para com o trabalho realizado em sala de aula.

O tema motivação ligado à aprendizagem está sempre em evidência nos ambientes escolares, impelindo professores a se superar ou fazendo-os recuar, chegando à desistência nos casos mais complexos. Porém, ela tem um papel muito importante nos resultados que os professores e alunos almejam (MORAES; VARELA, 2007, p.6). 
Sem dúvida, buscar recursos que atraem os alunos e favoreçam a aprendizagem é uma tarefa inerente à docência e quanto a essa questão espera-se que os docentes se apresentem deveras empolgados quando percebem possibilidades de alcançar esse desejo. Mas em relação à adoção de práticas pedagógicas que incorporam os recursos das TIC é necessária certa cautela quanto a avaliação das reações dos alunos, pois segundo Pousts - Lajus e Riché -Magnier (1998, p. 105) "como não nos questionarmos se o efeito observado não resultará mais de uma atenção prestada ao aluno durante a experiência, de uma ruptura de rotina escolar, do que da própria tecnologia?".

Desta maneira, ressalta-se que são necessários que se desenvolvam mais estudos específicos concernentes aos efeitos desses recursos tecnológicos nos dispositivos psicológicos necessários a aprendizagem como motivação, gosto pelas atividades, atenção entre outros. Bem como, estes recursos podem contribuir para o desenvolvimento e estímulo de habilidades dos alunos.

Feitas as devidas ressalvas, acrescenta-se que mesmo carecendo de maiores investigações a respeito das reações apresentadas pelos alunos quanto ao uso das tecnologias, é válido defender que essa percepção dos docentes, ainda que de caráter pouco profundo, figura de antemão como um aspecto favorável à aprendizagem, uma vez que provavelmente estimula os docentes a buscar novas formas de ensinar e aprender aliadas a esses instrumentos.

No tocante às dificuldades apontadas pelos professores, verifica-se que a ausência ou restrição de Internet nos espaços escolares, falta de um apoio técnico para orientação e manutenção dos equipamentos e a escassez desses equipamentos são relatados com frequência. Mas, observa-se que ocorrem casos em que há escolas nas quais se apresentam as condições favoráveis para a realização de práticas inovadoras que incorporem essas tecnologias e muitas vezes isso não ocorre.

Além das dificuldades de ordem material (computador, Internet, softwares específicos, etc.), há a menção sobre a falta de conhecimento. Esse é um problema crucial, tendo em vista que conhecer as tecnologias disponíveis e experimentar e identificar suas possibilidades de uso em diferentes práticas de ensino é uma exigência que se impõe aos docentes. "Para introduzir a tecnologia digital em práticas de ensino, o professor precisa saber que tais recursos existem, definir quais ele precisa e onde e como ele pode procurá-los" (BRAGA, 2013, p. 21). Entre as Dificuldades Enfrentadas no processo de utilização das tecnologias nas Salas de Recursos:

-Falta ou restrição de acesso à internet; -Em algumas situações realça as limitações dos alunos;

-Necessidade de reaplicação e verificação a médio e longo prazo das tecnologias e aplicação em outros contextos para verificar a contribuição para a aprendizagem;

-Falta de conhecimento;

-Ausência de suporte técnico na área da informática;

De fato, o emprego dos recursos tecnológicos nas atividades de ensino surge como um desafio para os professores. Nesse sentido, Pedro Demo (2009, p. 59) lembra que um dos problemas enfrentados pelos professores é a falta de fluência ou habilidades para lidar com as tecnologias e para aplicá-las na aprendizagem. A respeito do papel da instituição na formação docente, o mencionado autor declara que "a instituição precisa oferecer habilidades técnicas, inclusive reservadas, ainda que a maneira mais profícua de aprender seja por prática pessoal e interação com pares".

Sobre as TIC é interessante observar que são instrumentos que produzem por si só, dificuldades para o domínio das mesmas. Na opinião de Pousts - Lajus e Riché - 
Magnier (1998, p.91) ainda que a utilização dessas tecnologias seja frequente e que haja familiaridade dos usuários com as mesmas, estas "são e continuarão a ser provavelmente durante muito tempo de abordagem difícil, devido ao seu funcionamento intrinsecamente complexo, mas também à evolução contínua das ferramentas na busca de, mais funções, mais possibilidades".

Diante dessa problemática, os docentes devem imitar a postura dos alunos, que na maioria das vezes adquirem conhecimentos e habilidades para lidar com essas ferramentas a partir de iniciativas próprias, impulsionados pela curiosidade e interesse em desvendar esse "mundo novo". Essa é uma das sugestões que vão de encontro a proposta de Pousts - Lajus e Riché -Magnier (1998), que indicam o retorno ao estado de aluno/aprendiz. Na opinião dos referidos autores, as competências necessárias para utilizar as ferramentas tecnológicas não podem ser aprendidas da mesma forma que os saberes escolares tradicionais, pois estas fazem desaparecer as fronteiras que delimitam a educação formal. "A sua difusão tende espontaneamente a realizar-se de maneira informal; é uma constatação válida tanto para os professores quanto para os alunos" (p. 199).

Argumentos contrários à parte, um dos requisitos das novas alfabetizações é saber utilizar as tecnologias vigorantes nos dias de hoje. Deste modo, entre tantas limitações e desafios a serem enfrentados, defende-se que a realidade não aponta só entraves às transformações das práticas educacionais, mas assinala a importância da educação permanente e do investimento incessante na capacitação docente.

Cabe, pois, defender a ideia de formação permanente associada tanto a educação informal quanto a educação formal, pois ambas se complementam. A formação contínua aliada às vivências práticas e trocas de saberes entre os pares pode auxiliar os educadores a acompanharem esse movimento de transformação escolar. Movimento esse que na verdade não emergiu agora, mas apenas se tornou mais visível à medida que a geração dos denominados nativos digitais reivindica uma educação centrada nas demandas do contexto social.

\section{CONSIDERAÇÕES FINAIS}

As TIC chegaram à escola e se mostram como instrumentos promissores para modificar as práticas pedagógicas. Além dessas expectativas positivas, acarretam também grandes desafios aos profissionais da educação.

No tocante a utilização dessas tecnologias no AEE, as condições de emprego muito se assemelham a realidade vivenciada em outras modalidades educacionais. Os problemas que mais comumente são identificados em outros espaços e localidades do sistema educacional se repetem nas Salas de recursos.

De forma similar, assim como se projetam grandes expectativas quanto as possibilidades de contribuição dos recursos provenientes das novas tecnologias para os alunos considerados "sem deficiência", igualmente se cogitam grandes realizações ao AEE e efeitos benéficos ao seu público - alvo.

As práticas pedagógicas desenvolvidas com as TIC podem ser consideradas embrionárias diante das possibilidades atribuídas a esses recursos, em parte pelos problemas enfrentados nos ambientes escolares, e em parte pela falta de conhecimento e de oportunidades de experimentar os recursos e assim descobrir suas potencialidades para o processo de ensino e aprendizagem.

Outrossim, é evidente a necessidade de maiores investigações sobre as questões referentes ao uso das tecnologias no AEE e principalmente no sentido de identificar mais funcionalidades desses recursos que sirvam ao intento de garantir condições de escolarização para os alunos com necessidades educacionais especiais. 
É imperativo também que estudos sejam realizados também no sentido de conhecer as formas e possibilidades de realizar a avaliação dos resultados obtidos pelos alunos quando se utilizam das práticas pedagógicas incorporadas às TIC, buscando inclusive a elaboração de ferramentas digitais que possam auxiliar nesse trabalho.

\section{AGRADECIMENTOS}

Bolsa de Produtividade em Pesquisa BEPP-00013/16 - Fundação de Amparo à Pesquisa do Maranhão - FAPEMA

\section{REFERÊNCIAS}

ALVES, D. O. et.al. Sala de Recursos Multifuncionais: espaços para atendimento educacional especializado. Brasília: MEC/SEESP, 2006.

BORGES - ANDRADE, J. E. et. al. Treinamento, desenvolvimento e educação em organizações e trabalho: fundamentos para a gestão de pessoas. Porto Alegre: Artmed, 2007. Disponível em: < https://books.google.com.br>. Acesso em jan. 2016.

BRAGA, D. B. Ambientes Digitais: reflexões teóricas e práticas. 1 ed. São Paulo: Cortez, 2013.

BRASIL. Constituição da República Federativa do Brasil de 1988.

BRASIL. Decreto $\mathbf{n}^{\circ} \mathbf{7 . 6 1 1}$, de 17 de novembro de 2011. Disponível no site: <http://www.planalto.gov.br/ccivil_03/_ato2011-2014/2011/decreto/d7611.htm>. Acesso em dez. 2015.

BRASIL. Lei de Diretrizes e Bases da Educação Nacional. Lei no 9.394, de 20 de dezembro de 1996. Disponível no site: 〈http://portal.mec.gov.br/arquivos/pdf/ldb.pdf〉. Acesso em dez. 2015.

BRASIL. MEC/SEESP. Política Nacional de Educação Especial na Perspectiva da Educação Inclusiva. 2008. Disponível em: 〈http://portal.mec.gov.br〉. Acesso em dez. 2015.

BRASIL. Ministério da Educação. Portaria Normativa no 13, de 24 de abril de 2007. Disponível no site: <http://portal.mec.gov.br/arquivos/pdf/multifuncional.pd>. Acesso em 25 de out. 2015.

BRASIL. SDHPR. Ata VII, 2007 do Comitê de Ajudas Técnicas. Disponível no site: <http://www.infoesp.net/CAT Reuniao_VII.pdf> Acesso em: 26/09/2015.

BRASIL/CEB. Diretrizes Operacionais para o Atendimento Educacional Especializado na Educação Básica, modalidade Educação Especial. 2009. Disponível em: <http://portal.mec.gov.br>. Acesso em dez. 2015.

DEMO, P. Educação hoje: "novas tecnologias, pressões e oportunidades. São Paulo: Atlas, 2009.

MINETTO, M. F. Currículo na Educação Inclusiva: entendendo esse desafio. $2^{\mathrm{a}}$ ed. Curitiba: IBPEX, 2008.

SANTOS, L. P.; PEQUENO, R. Novas tecnologias e pessoas com deficiências: a informática na construção da sociedade inclusiva? In: SOUSA, Robson Pequeno MOITA, F M. C.S. C.; CARVALHO, A.B. G. (Org.). Tecnologias digitais na educação. Campina Grande: EDUEPB, 2011.

SANTOS, V. CANDELORO, R. Trabalhos Acadêmicos. Uma orientação para a pesquisa e normas técnicas. Porto Alegre: AGE, 2006.

SORJ, B.; GUEDES, Luís Eduardo. Exclusão Digital: problemas conceituais, evidências empíricas e políticas públicas. Artigo. Novos Estudos nº101, jul. 2005. SOUZA, T. M. F. Importância da mediação do professor auxiliar da educação especial a partir das tecnologias de informação e comunicação: percepções sobre a formação continuada.

Diálogos Educ. R., Campo Grande, MS, v. 2, n. 2, p. 44-52, novembro 2011. 